\title{
Metrics for assessing retailers based on consumer perception
}

\author{
Anastasii Klimin ${ }^{1, *}$, Dmitrii Tikhonov ${ }^{1}$, and Aleksei Efimov ${ }^{1}$ \\ ${ }^{1}$ Peter the Great Saint Petersburg Polytechnic University, Institute of Industrial Management, \\ Economics and Trade, Graduate School of Business Technologies. 195251, Saint Petersburg, Russian \\ Federation
}

\begin{abstract}
The article suggests a new look at trading platforms, which is called "metrics." Metrics are a way to look at the point of sale in a large part from the buyer's side. The buyer enters the store and make buying decision based on those factors that the seller often does not consider, or considers in part, because "does not see" them, since he is not a buyer. The article proposes the classification of retailers, metrics and a methodology for their determination, presents the results of an audit of retailers in St. Petersburg on the proposed methodology.
\end{abstract}

Key words: metrics, assessing, retailers, consumer perception

\section{Introduction}

The objective of the article to propose a new methodology for the classification of retailers, based on the Maslow pyramid. The authors offer 9 metrics for estimations of retailers, which allow to classify the shop to one of five categories, according to Maslow pyramid. The results of study of retailers of St. Petersburg on the offered methodology are given. In the conclusion of the article authors indicate problems in the application of the proposed methodology and show directions for its development and improvement.

Most classifications of retailers are based on size, range, price level, parameters of the layout of goods in the point of sale, location of stores and other parameters [1-4]. Practically there are no classifications of stores, based on motivational and psychological characteristics of buyers. This study proposes a classification of retail stores based on the Maslow pyramid [5], considering the traditional classification criteria, which are listed above. This classification can be applied not only to FMCG stores, but also, for example, to clothing stores, other products of the $\mathrm{B} 2 \mathrm{C}$ markets. In addition, it can be extended to the classification of any sales tools, which we call "trading platforms", for example, to glossy real estate magazines (apartment, houses, etc.) or Internet sites about restaurants.

Retailers are divided into five categories corresponding to the levels of the Maslow pyramid and one additional, which is called "no category". The higher the declared category, the higher the impression of customers about the store, where customer can satisfy different levels of its needs, that is, to receive ever deeper satisfaction from the

\footnotetext{
${ }^{*}$ Corresponding author: klimin@kafedrapik.ru
} 
purchase according to the Maslow pyramid. In Table 1 you can see the proposed classification.

Table 1. Classification of retailers according to the Maslow pyramid

\begin{tabular}{|c|c|c|}
\hline $\begin{array}{c}\text { Number of Maslow pyramid } \\
\text { level }- \\
\text { category of retailer }\end{array}$ & $\begin{array}{c}\text { Name of Maslow } \\
\text { pyramid level }\end{array}$ & Type of retailer category \\
\hline 0 & No category & Street sellers \\
\hline 1 & Physiological needs & Tent, pavilion. \\
\hline 2 & Safety needs & $\begin{array}{c}\text { Convenience store, } \\
\text { shop near the house. }\end{array}$ \\
\hline 3 & Social belonging & $\begin{array}{c}\text { Network retail, } \\
\text { corporate system }\end{array}$ \\
\hline 4 & Esteem & Specialized store \\
\hline 5 & Self-actualization & Boutique \\
\hline
\end{tabular}

Briefly describe the categories of stores.

1. Tent, pavilion - "Physiological needs", "Survival"

These small shops sell goods of daily demand, such as vegetables, milk, bread, packaged products. The advantage of these points of sell is that they have high mobility, thanks to which it is possible to place a tent or pavilion near potential buyers, and reduce the time for the purchase of products. This is the lowest level in the pyramid, where the consumer buy, when "very hungry". In such places, there is a minimum of comfort, convenience and assortment.

2. Convenience store, shop near the house - "Safety".

The pavilion does not guarantee safety, the level of sanitation there can be quite low, there is often no place for buyers (a shopping hall), the goods are given away from a window or through a counter to the street. The store near the house is not a network retail, it is targeted for buyers who live near the store. In most cases, this marketplace is located within a radius of 500 meters from the house, that is, "within walking distance", which is undoubtedly a significant advantage for buyers. Unlike the tents and the pavilions, they have a trading hall, some standards of sanitation and hygiene are observed.

3. Network retail, corporate system - "Social belonging".

Network retailers - the most common in modern conditions, the form of trade in the FMCG markets. In the opinion of the authors, it corresponds to the third level of the Maslow pyramid, social belonging. Visitors to network stores select them in accordance with their social status and buying behavior and visit those stores in which they see the same as they are buyers. A network store creates a sense of belonging to a certain class of people. In terms of trading formats, network retailers are divided into supermarkets, hypermarkets, discount stores, etc. Depending on this, their category according to the system proposed by the authors can be stretched from 2 to 4 categories. The network supermarket can be closer to the convenience store or to a specialized store. When evaluating stores from this category, you can not compare stores of different formats, for example, supermarkets with hypermarkets.

4. Specialized store - "Esteem".

In these stores specialization is carried out by assortment. An example are specialized stores that sell only fruits, vegetables, smoked fish or trade only with meat from Argentina. Wine stores are also classified as specialized. This category of stores is clearly different 
from the others, as in the specialized stores there is a clear division of the product line. In this regard, such stores are difficult to compete with large networks due to the lack of choice of other categories of goods. Despite this, a deep and wide assortment of a special product is a significant advantage of specialized stores. High quality of service and qualification of personnel is one of the decisive factors when choosing this store for purchase. Buyers come to specialized stores when they want to purchase the best quality and taste, comparing it to other products from the same category. In this way, they realize the need for esteem.

5. Boutique - "Self-actualization".

A boutique is a store in which all aspects of its activities are at a high level, including the price. It is important to understand that the buyer is willing to pay a lot of money for the appearance of the store, the quality of the goods, the high level of service, etc. The assortment in such stores is rather deep (even unique), than wide. The buyer compares himself with this place, that is, for him it is no longer just a store, but a manifestation of self, self-actualization through the store. Also, the buyer can go to a boutique, because he refers himself to a social group, in which a visit, for example, of the "Azbuka Vkusa" ("The $\mathrm{ABC}$ of Taste") store in St. Petersburg is a manifestation of good taste and style. In most cases, these stores are preferred by high-income buyers who are willing to pay for a high class of service, beautifully decorated store interior, unique products and presentation of the best.

We can identify the five most expensive stores in St. Petersburg at the cost of some "boutique" consumer basket. The price of the basket includes the maximum price for $1 \mathrm{~kg}$. cheese, the price for $1 \mathrm{pc}$. oysters and the price for the most expensive bread in the store. Below is a list of food boutiques in St. Petersburg in descending order of the value of such a consumer basket:

1. "Eliseevsky". 7740 rubles / 120 euros (http://www.kupetzeliseevs.ru);

2. The Globe of Gourmet. 5450 rubles / 83 euros (https://globusgurme.ru);

3. The ABC of Taste. 5406 rubles / 83 euros (http://spb.av.ru);

4. "Super Babylon". 5187 rubles. / 80 euros (http://www.superbabylon.ru);

5. "Le Land 24" 4851 rubles. / 75 euros (http://supermarket-land.ru).

\section{Metrics}

The authors identified 9 metrics, which are used to evaluate retailers. Metrics are divided into subjective and objective. Subjective metrics depend on the greater degree of the buyer's impressions, the objective metrics can be assessed by certain quantitative characteristics. Actually, the division into subjective and objective metrics is very arbitrary. Objective metrics are not calculated by formulas, and, like subjective ones, are estimated by the buyer's opinion. The authors have not yet reached the final decision on the classification of metrics.

Subjective metrics:

1. Perception;

2. Safety;

3. Accessibility to the product;

4. Showcase and display of goods.

Objective metrics:

5. Price range;

6. Assortment line;

7. Tastes;

8. Attraction;

9. Staff. 
Metrics are estimated on a 5-point scale which corresponds to the classification of retailers: from the tent ( 1 point) to the boutique (5 points). In the next part, we will describe the methodology for estimating.

We briefly describe the metrics.

1. Perception. This metric includes the appearance of the store outside, parking, the first impression of the entrance to the store, the smells, the benevolence / tension of the overall situation in the store, the type of guard and his behavior, the cleanliness of the floor, the presence of a toilet, etc. Based on this metric, the buyer has a first positive or negative attitude to the store.

2. Safety. This metric includes hygiene and sanitation, lighting of shelves and store, type of store visitors, cleanliness and quality of trolleys and baskets, product presentation on shelves, convenient walkways, discernable price tags, etc.

3. Accessibility to the product. Is it possible to taste the product, is it convenient to take it, can you choose the fruit and vegetables yourself, is there enough of the goods on the shelf (there are plenty to choose from), are there different sizes of the packaging (for example, bottles of water of different volumes), what is the queue at the ticket offices, etc.

4. Showcase and display of goods. Window dressing, neatness of the shelves, beauty and accuracy of the laying out of the goods, absence of empty shelves, order on shelves, availability of accompanying goods, lack of redundant advertising materials, design of a trading hall.

5. Price range. Is there a division of goods into "very cheap", "cheap", "expensive", "very expensive". Whether the store uses loyalty programs for regular customers, whether there are sales.

6. Assortment line. Does the store always have the necessary goods (daily - "bread"), can you buy goods that are purchased less often and are expensive (weekly - "meat"). How much is represented in the store of product categories; whether there are goods "for the soul", which are not bought on the "list", but are picked up "to relieve stress". Whether it is possible to buy the goods for a holiday (flowers, gifts, etc.).

7. Tastes. Is there a variety of tastes in the range, for example, different varieties of tomatoes. Whether there is at shop "some special trait" in assortment ("only in this shop"). Does the store offer fresh products (freshly baked bread or fresh salads), etc.

8. Attraction (Involvement. Enthrallment) Innovation, not boredom, management of the buyer's behavior: can the buyer "come for milk, and leave shop with a whole cart of what he was not going to buy."

9. Staff. Goodwill, presence in the workplace, awareness, sociability, unobtrusiveness, ability to give the necessary advice.

\section{Assessment methodology}

As we have already said, the score for each metric is 5-point scale. You can put not only the whole points $(1,2,3,4,5)$, but also fractional, for example, 2,4. Points correspond to categories of shops. The evaluation is made by experts-buyers who should have the impression of shops of each category. If an network retail store is estimated, the expert understands that for such a store a normal score is "3" and if he wants to put, for example, 3.6 points in the "Tastes" metric, then he should have for this justification that such the choice of tastes is more characteristic of a specialized store, and not of a supermarket. This is the difficulty of rating points. To obtain stable and reasonable estimates it is necessary to have a staff of experts-buyers who have the following characteristics.

1. The expert visited shops of different categories and has an idea about each of them. 
2. The expert has experience of shopping in shops, because you cannot evaluate the "Attraction" metric, if you do not really try to buy something in the store and experience the involvement.

3. The expert visited many shops of the same category, for example, different retail stores and can compare the shopping experience in each of them.

The work of the buyer expert is somewhat like that of the inspector "Le Guide Rouge" of Michelin [6]. It is necessary to have a lot of experience and a formed coordinate system to evaluate the metrics. Training of experts-buyers begins with a joint visit to stores of different categories and an explanation of what character is the metric, how and for what we can raise or lower the score for a certain metric.

\section{The results of the study}

For the study, the network hypermarkets FMCG of St. Petersburg category 3 were chosen. This choice was because among the stores of this category there is a fierce competition and it would be desirable to assess their positions on the metrics in the competitive struggle. Another reason for choosing the third category was that corporate networks are the easiest to study, the most common compared to other categories of stores. Also, representatives of various corporate networks are easy to compare with each other, because all network stores are organized on the same principles, which you cannot say, for example, about specialized stores

The study took place in February-March 2016, it was attended by participants of the Foresight Club of St. Petersburg, students and teachers of the Peter the Great St. Petersburg Polytechnic University, in total there were 42 shops in 16 corporate networks.

The results of the metering of six stores from the trade networks "Auchan", "OKEY" (2 shops), "Lenta" and "Carousel" (2 shops), for which the greatest amount of data was obtained are given in Tables 2-4. The achieved category is calculated as a simple average of nine metrics. The indicator of the competitive position is calculated by dividing the reached category to the declared category (in our case 3) and is expressed as a percentage of the declared category. For example, if the achieved category is 3.25 points, then the competitive position for the declared category 3 will be $108.3 \%$.

Table 2. The average value of metrics from the first to the fifth

\begin{tabular}{|c|r|r|r|r|r|}
\hline Shop & Perception & Safety & $\begin{array}{c}\text { Accessibility } \\
\text { to the product }\end{array}$ & $\begin{array}{c}\text { Showcase } \\
\text { and display } \\
\text { of goods }\end{array}$ & Price range \\
\hline "Auchan" & 2.6 & 2.4 & 2.8 & 2.4 & 3.8 \\
\hline "Lenta" & 2.4 & 2.2 & 2.8 & 2.4 & 2.9 \\
\hline "OKEY" 1 & 4 & 3.7 & 3.8 & 3.8 & 4.1 \\
\hline "OKEY" 2 & 1.7 & 2.4 & 2.5 & 3 & 3.4 \\
\hline "Carousel" 1 & 1.8 & 1.8 & 2.4 & 1.8 & 2.8 \\
\hline "Carousel" 2 & 3.3 & 2.7 & 3 & 2.8 & 2.8 \\
\hline
\end{tabular}


Table 3. The average value of the metrics from the sixth to the ninth and the achieved category

\begin{tabular}{|c|r|r|r|r|r|}
\hline Shop & Assortment line & \multicolumn{1}{|c|}{ Tastes } & \multicolumn{1}{c|}{ Attraction } & \multicolumn{1}{c|}{ Staff } & \multicolumn{2}{c|}{$\begin{array}{c}\text { Achieved } \\
\text { category }\end{array}$} \\
\hline "Auchan" & 3.6 & 3 & 2.6 & 2.8 & 2.9 \\
\hline "Lenta" & 3.3 & 3.2 & 2.4 & 3.3 & 2.8 \\
\hline "OKEY" 1 & 4 & 3.8 & 3.3 & 3.3 & 3.8 \\
\hline "OKEY" 2 & 3.9 & 3.3 & 2.8 & 3.1 & 2.9 \\
\hline "Carousel" 1 & 2.9 & 1.8 & 2.3 & 1.5 & 2.1 \\
\hline "Carousel" 2 & 3.1 & 2.1 & 2.9 & 3.2 & 2.9 \\
\hline
\end{tabular}

Table 4. Summary rresults

\begin{tabular}{|c|r|r|r|}
\hline Shop & \multicolumn{1}{|c|}{$\begin{array}{c}\text { Achieved } \\
\text { category }\end{array}$} & \multicolumn{1}{c|}{$\begin{array}{c}\text { Declared } \\
\text { category }\end{array}$} & \multicolumn{1}{c|}{$\begin{array}{c}\text { Competitive } \\
\text { position }\end{array}$} \\
\hline "Auchan" & 2.9 & 3 & $96.7 \%$ \\
\hline "Lenta" & 2.8 & 3 & $93.3 \%$ \\
\hline "OKEY" 1 & 3.8 & 3 & $126.7 \%$ \\
\hline "OKEY" 2 & 2.9 & 3 & $96.7 \%$ \\
\hline "Carousel" 1 & 2.1 & 3 & $70 \%$ \\
\hline "Carousel" 2 & 2.9 & 3 & $96.7 \%$ \\
\hline
\end{tabular}

The calculated competitive positions should be compared with the performance indicators of the stores: revenue per square meter of sales area, average purchase size [7].

\section{Discussions and Conclusions}

The level of competitiveness among stores that are part of the same network is not the same. There are stores "good" and "bad", but the overall level of the network is traced. The quality of the network of stores can also be characterized by the level of deviation of the achieved category from the declared category for all stores of network. Based on the results of the research, the first place was the network of hypermarkets "OKEY".

The values of the points awarded depend very much on the experts-buyers who put the valuations. Ideally, you need to have an unchanging homogeneous group of professional experts-buyers who visit the same shops. In our study, experts were people of different ages, social status, customer experience. This does not allow us to say that research gives us adequate and uniform estimates of stores.

Metering should be done several times a year for investigating changes in the values of different metrics. The most significant changes occur after repairs and reconstruction of trading floors, with the change of management of the company, mergers and acquisitions of retail networks. 
The most difficult problem is the selection and preparation of experts-buyers. Before conducting a research with experts, it is necessary to conduct theoretical and practical installation exercises on which the theory of metrics is declared. The most important part of the classes is the explanation of the categories of shops on the Maslow pyramid. Many experts in the beginning cannot perceive the scale of assessments from 1 to 5 points correctly, believe that if the store is "good", then it should get 5 points. However, a third category store can receive 5 points only in some cases, for example, for an assortment, if it corresponds to a store of the fifth category. For this, it is necessary to conduct trainings with experts in real stores of different format categories for all metrics.

The conception of the store categories and their evaluation by metrics will probably be very different for different cities and other regions. Even the same retailers in different countries offer different levels of service, assortment, are differently designed, use different trade equipment. The difference in quality and in the concepts of specialized stores and boutiques will be even more significant. In the opinion of the authors, according to the proposed methodology, one cannot evaluate the quality of stores based on data on the number of goods presented in stores, the size of stores, and big data on people's behavior [8]. The presented methodology refers to the direction of subjective, psychological instruments of perception of stores by specific buyers in a particular place.

\section{References}

1. V. K. Yurtaeva, Development of a modern retail format "hard discounter" as a tool for effective positioning in difficult economic conditions. $M M R, 3(129), 186-200$ (2017)

2. M. G. Clifford, Classifications of retail stores and shopping centres: some methodological issues. GJ, 45, 255-264 (1998)

3. A. I. Klimin, Current trends in stimulating consumers at points of sale. STL of SPbPU ES, 6(209), 200-207 (2014)

4. A. Kovalenko, A. Polevoy, Competitive Strategies for Retail Food Networks. Classification and Empirical Analysis (2017)

5. A. H. Maslow, A Theory of Human Motivation. PR, 50, 370-396 (1943)

6. L. Karpik, Michelin's red guidebook. ST, 42, 369-389 (2000)

7. A. I. Klimin, A. A. Zakharova, Analysis of the effectiveness of incentive measures in retail. $A F A$, 6, 305-331 (2009)

8. T. Khvatova. Big Data is watching YOU: opportunities and challenges from the perspective of young adult consumers in Russia, $J M M, 33$, 719-741 (2017) 
